\title{
Prevalence of HIV in North-East Nigeria: A Case of Comprehensive HIV Service Delivery in 3 Internally Displaced Persons Camps in Borno State, Northeast, Nigeria
}

\author{
Nsikan Affiah*, Sunkanmi Fadoju, Paul Yunana, Jummai Adamu, Ndifreke James, Peter Dickson, \\ Joseph Jasini, Emmanuel Opada, Henry Udenenwu, Jonah John
}

Achieving Health Nigeria Initiative, Maiduguri, Nigeria

Email address:

afixilinosky@gmail.com (N. Affiah)

${ }^{*}$ Corresponding author

\section{To cite this article:}

Nsikan Affiah, Sunkanmi Fadoju, Paul Yunana, Jummai Adamu, Ndifreke James, Peter Dickson, Joseph Jasini, Emmanuel Opada, Henry Udenenwu, Jonah John. Prevalence of HIV in North-East Nigeria: A Case of Comprehensive HIV Service Delivery in 3 Internally Displaced Persons Camps in Borno State, Northeast, Nigeria. International Journal of HIV/AIDS Prevention, Education and Behavioural Science. Vol. 6, No. 2, 2020, pp. 62-66. doi: 10.11648/j.ijhpebs.20200602.15

Received: October 30, 2020; Accepted: November 11, 2020; Published: November 19, 2020

\begin{abstract}
The humanitarian crisis in North-East Nigeria has had its greatest impact in Borno, Adamawa and Yobe states who now depend largely on humanitarian assistance for their survival. According to the 2017 UNDP estimates, 8.5 million people are caught in the middle of the humanitarian crises in Northeast Nigeria, resulting in widespread displacement, insecurity, destroyed infrastructure and collapsed basic services. This setting presents context of fragility, vulnerability and uncertainties, which encourages and exacerbates HIV transmission. The relationship between HIV, humanitarian emergencies and prolonged conflict is multifaceted and complex. The recent 2019 NAIIS reported HIV prevalence in Borno state to be $1.3 \%$, however in the IDP camps, the risk of transmission appears to increase due to inadequate access to HIV and other basic health services. This study is aimed to determine the prevalence of HIV infection and uptake of comprehensive HIV services in 3 IDP camps; Ngala, Banki and Dikwa Local Government Areas of Borno state. The study adopted a case study approach with sample size of 26,712 individuals who were counseled and tested for HIV. The collected data was analyzed using STATA14. The result of study revealed the prevalence of HIV in the 3 IDP camps to be $0.98 \%$. In Ngala Camp, Ngala LGA of Borno state, there was a high prevalence rate of $1.98 \%$, which is higher than the Borno state's and the National indices. The HIV testing Uptake was estimated to be $56.31 \%$ across the 3 camps. Improved awareness to HIV infection and sustained service provision will enhance good health seeking behavior and reduce incidence of HIV infection and stigmatization of affected persons in the IDP camp.
\end{abstract}

Keywords: HIV Prevalence, Internally Displaced Persons (IDPs), Humanitarian, Borno State

\section{Introduction}

HIV/AIDS has been one of the leading causes of morbidity and mortality in the world [12]. Globally, in 2016, there were 36.7 million people living with HIV and 1 million AIDS related deaths [13]. In Africa, the HIV/AIDS burden stands at 25.7 million HIV-infected individuals, with more than two-thirds of new HIV infections globally [14]. Sub-Saharan Africa contributed $76 \%$ of the total HIV-infected people and $75 \%$ of the total HIV/AIDS deaths in 2015 [15]. To eradicate HIV/AIDS, the United Nations General Assembly set the 90-90-90 targets for HIV diagnosis, treatment, and viral suppression as part of the sustainable development goals [16]. By 2020, according to this target plan, it is expected that $90 \%$ of all PLHIV will have their HIV status known, $90 \%$ of diagnosed HIV cases will have received sustained antiretroviral therapy (ART), and $90 \%$ of people receiving ART will have viral suppression [12].

Conflict-induced displacement makes affected populations more vulnerable to HIV transmission. However, this vulnerability does not always necessarily translate into more HIV infections [17]. The extent to which conflict and 
displacement affect HIV transmission depends upon numerous competing and interacting factors such as loss of livelihoods; availability of education; the type and the duration of conflict; the pattern of living arrangements and conditions of internally displaced persons (IDPs), whether formal or informal settlement; the setting of their new location; and the overall access to health services, including HIV and sexual and reproductive health programs. These factors also have direct implications for HIV vulnerability [17].

In the North-East Nigeria, the humanitarian crisis has had its greatest impact in Borno, Adamawa and Yobe states that now depend largely on humanitarian assistance for their survival. According to the $2017 \mathrm{UN}$ estimates, 8.5 million people are caught in the middle of this crises resulting in widespread displacement, insecurity, destroyed infrastructure and collapsed basic services [10]. Humanitarian setting presents context of fragility, vulnerability and uncertainties, some of which encourage and exacerbate the risk of HIV transmission. The association between HIV, humanitarian emergencies and prolonged conflict is a multifaceted one. However, the challenges presented by emergencies do not always translate into increased infections. The spread of HIV during crises is always context specific [1,8]. Conflicting factors such as reduced mobility and access to an area, and in the case of some refugee camps improved protection, health, education and social services, may contribute to a decreased spread of HIV. However, the breakdown in social structures leads to risky behavior and often increases vulnerability to HIV infection $[1,6]$.

The inadequate coordinated national response to HIV prevention among internally displaced persons (IDPs) and refugees is worsened by the exclusion of this vulnerable groups from major national and Multi-country funded HIV/AIDS programs [3]. The concept of shared refugee caseloads across countries adopted by Great Lakes Initiative on HIV/AIDS funded by World Bank is an example of a well-funded regional approach to addressing HIV/AIDS in conflict-affected regions [11]. With this approach, the specific attention paid to refugees and other displaced persons would suggests that HIV vulnerability and risk can be managed and mitigated in some contexts during emergencies. However, overcoming barriers to treatment, targeted prevention services and the protection of patients' rights are key. Populations most at risk of HIV transmission in times of instability (such as women, sex workers and men who have sex with men) may become more vulnerable during humanitarian crises as existing forces of marginalization intensify and their needs are de-prioritized. Existing poor infrastructure and prolong emergency or conflict only means there is little relief for the affected persons [1,2].

The recently publicized NAIIS 2019 reported HIV prevalence in Borno state to be $1.3 \%$, this is not too far from the national prevalence which is now $1.4 \%$. The state is also estimated to have recorded only $28 \%$ treatment coverage which means there is a likelihood of several new undetected cases in the population [5]. However, in the IDP camps, the risk of transmission has increased due to inadequate HIV services. Unfortunately, when we look at internally displaced persons (IDPs), we don't have sufficient data to come to a firm conclusion about the relationships between conflict and prevalence of HIV/AIDS [9, 7]. The breakdown of social cohesion, lack of income, shortage of food, sexual violence, increased drug use and the disruption of health, education and infrastructure that characterize complex emergencies all contribute to putting populations affected by these crises at greater risk of HIV and present challenges for those already living with the virus [1]. On this note, this study aimed at determining the prevalence of HIV infection and uptake of comprehensive HIV services in 3 Internally Displaced People's camps in Borno State located in the Nigeria Northeast region. In addition, the study aimed at examining the causal effect between HIV prevalence and uptake of HIV TESTING in the 3 IDPs camps.

\section{Materials and Methods}

\subsection{Study Design}

A cross sectional study design approach was used case study approach was adopted.

\subsection{Study Population/Areas}

The study was conducted across comprehensive HIV service delivery points under the Global Fund Impact HIV Project in 3 main Internally Displaced People's (IDP) camps located in 3 LGAs (Bama, Ngala and Dikwa) of Borno State. The study period was d for 12 months (from January 2018 to December 2018).

\subsection{Sample Size}

A total of 26,712 individuals who were counseled and tested for HIV during the period was considered.

\subsection{Data Collection Method}

Data were routinely collected from the general population (excludes pregnant women) using data capturing tools such as the facility attendance register, client intake form, request and result form, HTS register, HIV and syphilis worksheet, summary forms etc.

\subsection{Method Data Analysis}

Data showing baseline characteristics such as aggregate test results and facility attendance where analyzed using STATA 14 statistical software. However, Correlation Analysis was deployed to show relationship between prevalence and uptake of HIV services.

\subsection{Exclusion Criteria}

All pregnant women who were confirmed using serum $\beta \mathrm{HCG}$ testing was excluded from this study.

\section{Results}

Findings from the study showed that the prevalence rate of HIV in the 3 IDP camps were 1.98\% (Ngala), 0.59\% (Banki) 
and $0.38 \%$ (Dikwa). The average prevalence across the 3 camps is estimated at $0.98 \%$. The finding also depicts that uptake of HIV Testing Services across the 3 sites were $51.19 \%$ (Ngala), 77.19\% (Banki) and 40.56\% (Dikwa), an average of $56.31 \%$ across the 3 camps. This means that the uptake of HIV service in Dikwa is low compared to Banki and Ngala. It is observed that there is no significant correlation $(\mathrm{r}=0.12)$ between prevalence of HIV and uptake of HIV service in 3 IDP camps.

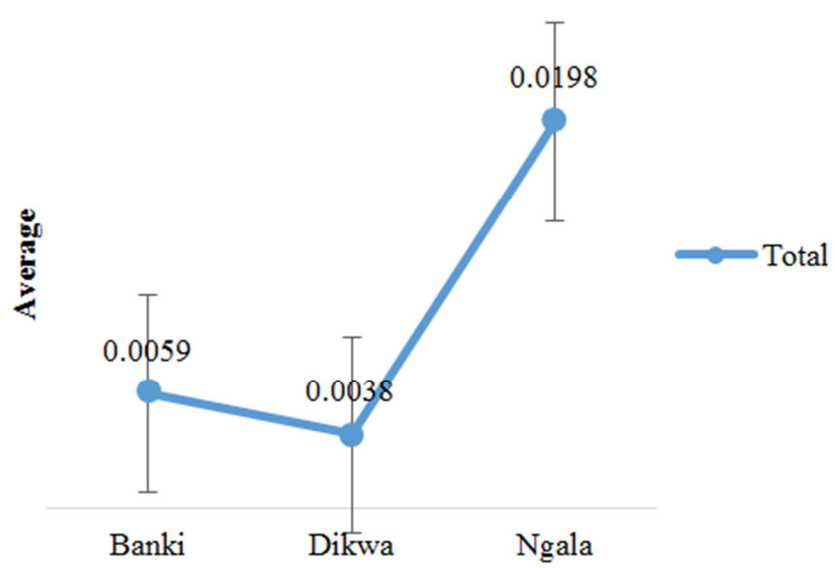

Figure 1. Prevalence of HIV in the 3 IDPs camp, Northeast Nigeria.

\subsection{Hypothesis Testing: Correlation Analysis Showing the Relationship Between Prevalence and Uptake of HIV Services in Northeast Nigeria}

$\mathrm{H} 0$ : There is no relationship between prevalence and uptake of HIV services in Northeast Nigeria

The correlation above depicts the extent of relationship between prevalence and uptake of HIV services among pregnant women in the 3 IDP camps. The result revealed that there is a weak negative correlation $(\mathrm{r}=0.12)$ between prevalence and uptake of HIV services in the 3 IDP camps in Northeast Nigeria.

Table 1. Correlation Analysis showing the extent of relationship between prevalence and uptake of HIV services in the 3 IDP camp.

\begin{tabular}{lll}
\hline & Prevalence & Uptake \\
\hline Prevalence & 1 & \\
Uptake & 0.12453 & 1 \\
\hline
\end{tabular}

\subsection{Hypothesis Testing: Regression Analysis Showing Effect Between HIV Prevalence and Uptake of HIV TESTING in the 3 IDPs Camps}

$\mathrm{H}_{0}$ : There is no causal effect between HIV prevalence and uptake of HIV TESTING in the 3 IDPs camps.

$\mathrm{H}_{1}$ : There is a causal effect between HIV prevalence and uptake of HIV TESTING in the 3 IDPs camp.

Table 2. Model Summary.

\begin{tabular}{lllll}
\hline c & R & R Square & $\begin{array}{l}\text { Adjusted R } \\
\text { Square }\end{array}$ & Std. Error of the Estimate \\
\hline 1 & $12453^{\text {a }}$ & 288 & -.424 & 4443.826 \\
\hline
\end{tabular}

a. Predictors: (Constant), Prevalence.
Table 3. $A N O V A^{a}$.

\begin{tabular}{|c|c|c|c|c|c|c|}
\hline \multicolumn{2}{|c|}{ Model } & $\begin{array}{l}\text { Sum of } \\
\text { Squares }\end{array}$ & Df & Mean Square & $\mathbf{F}$ & Sig \\
\hline \multirow{3}{*}{1} & Regression & 7981331.583 & 1 & 7981331.583 & \multirow[t]{3}{*}{404} & \multirow[t]{3}{*}{$639^{b}$} \\
\hline & Residual & 19747593.083 & 1 & 19747593.083 & & \\
\hline & Total & 27728924.667 & 2 & & & \\
\hline
\end{tabular}

a. Dependent Variable: Uptake.

b. Predictors: (Constant), Prevalence.

\section{Discussion}

This study used routine data (January to December 2018) from HIV/AIDS service delivery points in Banki, Dikwa and Ngala IDP camps. It reveals that the average prevalence across the 3 sites estimated at $0.98 \%$ is closely related to the recent survey by NAIIS which revealed the prevalence rate in Borno state to be $1.3 \%$ [5]. The prevalence of HIV has been found to increase in humanitarian emergencies due to factors such as breakdown in social structures, increase risky behaviors, inadequate education and stigmatization of affected person [4]. The situation is similar in these IDP camps in Northeast Nigeria where situation seem to be deteriorating day by day. The lack of coordinated effort towards the fight against HIV among the IDP camp population only fuels the situation making the population likely more vulnerable to increase infection. The high prevalence rate in Ngala IDP camp which also exceeds the national average is a major concern especially with its geographical location as a border town having boundaries with Cameroon and Chad where there is a constant movement of people across both sides of the border.

The study also shows $56.31 \%$ uptake of comprehensive HIV services across the three camps. Bearing in mind that the 90:90:90 strategy which was the corner stone of the Global Fund project strategy, the uptake of HIV services across the 3 sites is poor and it will be impossible to reach the strategic target. Information received from service providers following counseling sessions with clients showed a high level of stigmatization in the IDP camp for people living with HIV/AIDS. This may be due to lack of awareness or inadequate education which is common in emergency context where information on HIV may not be a high priority to the affected population [8] The result as shown in table 1 shows that there is no relationship between prevalence and uptake of HIV services because the correlation is weak $(\mathrm{r}=0.12)$.

From the model summary table, the $\mathrm{R}$ value $(0.12453)$ depict the correlation value between HIV Prevalence and uptake in the 3 IDP camps. From the result, there is a weak relationship between the two variables under study. Furthermore, from the model summary table the R-square i.e. the coefficient of determination (0.288) revealed that prevalence of HIV can be explained by $29 \%$ of only HIV service uptake. This by implication means that the remaining $71 \%$ can be explained by other variables which are not included in the study.

However, from the Analysis of Variance [ANOVA] table, the $[\mathrm{F}$-value $=0.404 ; \mathrm{p}$-value $=0.639]$ is greater than the bench-mark value of 0.05 . this connote that there is no 
significant effect between HIV prevalence and uptake of HIV testing in the 3 IDPs camps. i.e. HIV prevalence and uptake are not dependent on each other. Therefore, the $\mathrm{H}_{0}$ [Null hypothesis] is accepted.

\section{Conclusions}

This study represents the first-time routine HIV data that was collected over a period in an emergency context in the region. The prevalence of HIV was found to be higher in one of the IDP camps (Ngala) as compared to Banki and Dikwa IDP camps. High prevalence in Ngala is also higher than Borno State and National indices and there is need to develop an intervention to address the situation. Also, HIV service uptake was found to be lower in Dikwa as compared to Banki and Ngala this high HIV service uptake in Banki and Ngala may be due to their location as border towns between Nigeria and Cameroon. Due the porous nature of the border, this by implication means that people from other country came for HIV services in Banki and Ngala than Dikwa as depict from the study; the impact of this on the HIV prevalence in the population is a subject for further research. Also, HIV prevalence and uptake are not dependent on each other. The study recommends improved awareness of HIV infection and sustained services provision as these might likely enhance good health seeking behavior and reduce incidence of stigmatization of affected persons in the IDP camp.

\section{Consent}

Consent was obtained from all clients using the client intake form. This is a standard tool that has been approved by the Federal Ministry of Health for use in all HIV Counselling and Testing Services. The organization also obtained approval from the Borno State Agency for the Control of AIDS to go ahead with the study.

\section{Acknowledgements}

We gratefully thank Achieving Health Nigeria Initiative, for giving us the platform to carry out this study. We also thank FHI 360 team in the IDP camps, the Borno State Agency for the Control of AIDS and other key partners in Borno state. Authors are also thankful to the respondents of the study for providing valuable information regarding their HIV status.

\section{References}

[1] Avert. (2017). Humanitarian emergencies, armed conflict and the HIV response transmission. Addressing $\mathrm{HIV}$ in emergencies is not a matter of. Retrieved from www.avert.org/professionals/hiv-programming/emergencies-c onflicts-and-hiv-response.

[2] Avert. (2018). Women and girls, HIV and AIDS. Avert. Retrieved from https://www.avert.org/professionals/hiv-social-issues/key-affe cted-populations/women.
[3] Hanson, B., Wodak, A., Fiamma, A., \& Coates, T. (2008). Conflict Settings: Funding Recommendations. Aids, 22 (Suppl 2), 95-103. https://doi.org/10.1097/01.aids.0000327441.66656.da. Refocusing.

[4] Monjok, E., Smesny, A., \& Essien, E. J. (2009). HIV/AIDS-related stigma and discrimination in Nigeria: review of research studies and future directions for prevention strategies. African Journal of Reproductive Health, 13 (3), 2135. https://doi.org/10.2307/27802605.

[5] NACA. (2019). National Agency for Control of Aids, Nigeria: Revised National HIV and AIDS Strategic Framework.

[6] Samuels, F., Harvey, P., \& Bergmann, T. (2008). HIV adn AIDS Emergency Situations: Synthesis Report. Overseas Developmetn Institue, 44 (November). Retrieved from https://www.odi.org/sites/odi.org.uk/files/odi-assets/publicatio ns-opinion-files/4277.pdf.

[7] Spiegel, P., \& Harroff-Tavel, H. (2006). HIV / AIDS and Internally Displaced Persons in 8 Priority Countries. (January), $1-47$.

[8] UNAIDS. (2010). Guidelines for Addressing HIV in Humanitarian Settings (2010 revision). Retrieved from http://www.unaids.org/sites/default/files/media_asset/jc1767_i asc_doc_en_3.pdf.

[9] UNICEF. (2006). HIV / AIDS, Conflict and Displacement.

[10] UNOCHA. (2017). Humanitarian partners. Retrieved from www.humanitarianresponse.info/en/operations/nigeria.

[11] World Bank. (2005). Africa Region - Great Lakes Initiative on HIV/AIDS (GLIA) Support Project (English). Washington, DC: World Bank.

http://documents.worldbank.org/curated/en/188651468741666 540/Africa-Region-Great-Lakes-Initiative-on-HIV-AIDS-GLI A-Support-Project. Retrieved from http://documents.worldbank.org/curated/en/188651468741666 540/Africa-Region-Great-Lakes-Initiative-on-HIV-AIDS-GLI A-Support-Project.

[12] E. K. Mainaa, *, H. Mureithia, A. A. Adana, J. Muriukib, R. M. Lwembeb, E. A. Bukusi International Journal of Infectious Diseases 97 (2020) 151-158.

[13] UNAIDS. UNAIDS data 2017. 2017. https://www.unaids.org/en/resources/documents/2017/2017_d ata book. UNAIDS. UNAIDS data 2018. 2018. https://www.unaids.org/en/resources/documents/2018/unaidsdata-2018. UNAIDS. UNAIDS data 2019. 2019.

[14] WHO. World Health Organization, consolidated guidelines on the use of antiretroviral drugs for treating and preventing HIV infection, recommendations for a public health approach, 2013. 2018.

http://www.who.int/hiv/pub/guidelines/arv2013/download/en/i ndex.html.

[15] Wang H, Wolock TM, Carter A, Nguyen G, Kyu HH, Gakidou $\mathrm{E}$, et al. Estimates of global, regional, and national incidence, prevalence, and mortality of HIV, 1980-2015: the Global Burden of Disease Study 2015. Lancet HIV 2016.

[16] UNAIDS. Global AIDS response progress reporting 2014 construction of core indicators for monitoring the 2011 United Nations Political Declaration on HIV and AIDS. 2014. https://files.unaids.org/en/media/unaids/contentassets/docume nts/document/2011/JC2215_Global_AIDS_Response_Progres s_Reporting_en.pdf. 
[17] UNHCR / UNAIDS (2007). HIV-related Needs in Internally Displaced Persons and Other Conflict-affected Populations: A Rapid Situation Assessment Too. 